\title{
DETERMINANTS OF PERSISTENT AND TRANSIENT TECHNICAL EFFICIENCY OF MILK PRODUCTION IN EU
}

\section{Gabriela Trnková1, Zdeňka Žáková Kroupová2}

\footnotetext{
1 University of Hradec Králové, Faculty of Informatics and Management, Department of Economics, Czech Republic, ORCID: 0000-0001-5181-5689, gabriela.trnkova@uhk.cz;

2 Czech University of Life Sciences Prague, Faculty of Economics and Management, Department of Economics, Czech Republic, ORCID: 0000-0001-5834-3338, kroupovaz@pef.czu.cz.
}

\begin{abstract}
This paper deals with the estimation of technical efficiency of milk production in the EU, its decomposition and the analysis of determinants of transient and persistent efficiency. Attention was focused on specialized milk production using FADN data in the period from 2004 to 2017. The analysis is based on the four-component model that represents the most advanced approach to technical efficiency analysis at present and the multi-step estimation procedure extended by technical efficiency determinants. To the best of our knowledge, this is the first application of this model based on the multi-step estimation with the inclusion of technical efficiency determinants on this type of specialization in the EU. The results show that the overall technical efficiency achieves the mean value of $68 \%$ and is relatively dense around the mean. The persistent inefficiency poses a greater problem for dairy production and varies considerably across European regions compared to the transient part. Based on the assessment of the development of transient efficiency, it is evident that it is influenced by the situation on the dairy market, in particular by the milk crises. The most effective conversion of inputs to outputs is achieved in the Netherlands, the United Kingdom, and Belgium and is least burdened with institutional and structural rigidities. The results show that transient efficiency is positively influenced by paid labour share, rented land share, level of modernization and level of off-farm activities and negatively by the level of subsidies on livestock. The positive effect of the economies of size on persistent efficiency is not proved. However, specialization, despite the higher vulnerability of specialized farms to price shocks, affects persistent efficiency positively. Localization of farms in LFAs, as expected, has a negative impact on persistent technical efficiency.
\end{abstract}

Keywords: Technical efficiency, transient efficiency, persistent efficiency, four-component model, determinants, milk production.

JEL Classification: C23, D24, Q12.

APA Style Citation: Trnková, G., \& Žáková Kroupová, Z. (2020). Determinants of Persistent and Transient Technical Efficiency of Milk Production in EU. E\&M Economics and Management, 23(4), 39-54. https://doi.org/10.15240/tul/001/2020-4-003

\section{Introduction}

The evaluation of the competitiveness of different agriculture sectors has, traditionally, been based on the measurement of technical efficiency. We focus on the dairy sector because the EU dairy sector is one of the pivotal agricultural sectors in the EU. The dairy sector currently faces several challenges arising from growing EU and global demand, price volatility, fodder crisis as a result of climate change and the fact that dairy farms are highly specialized, which on the one hand may be an advantage, on the other hand a threat due to higher vulnerability to income shocks. 
Milk production is carried out on mixed farms or specialized farms. In 2012, the share of the sector covered by specialized farms in the FADN, on which this analysis is based, is more than $80 \%$ in the EU-15 (EU members until the 2004 enlargement) and around $50 \%$ in the other member states. There are big differences in coverage among EU countries: only $17 \%$ of milk production in Slovakia and $19 \%$ in the Czech Republic, but full production in Ireland and Finland. The specialized dairy farms are especially concentrated in the North-Western countries of the EU. According to the European Parliament (2018) farms in the EU-15 are in general much larger and have higher yields than in the EU-13 (after the 2004 enlargement including the United Kingdom). Stark contrasts also exist between EU countries and regions in terms of intensity and productivity of milk production. Moreover, differences in the competitiveness of each country may be influenced by different national policies.

The diversity of milk production in EU regions and countries is linked to the differences in natural potential as well as in the socialeconomic and regulatory context. Obviously, the ability of farms to convert inputs to outputs with the greatest possible efficiency is influenced by a number of determinants. The accurate measurement of the technical efficiency of dairy production requires an understanding of these differences in the working environment. The decomposition of the technical efficiency into short-term (transient) and long-term (persistent) part, which is done in this study and used the four-component model (named also the generalized true random-effects model GTRE), is a useful tool to understand the nature of inefficiency. However, Lien et al. (2018) mention, that without determinants one cannot explain systematic differences in inefficiency within and between farms. Therefore, GTRE in our research is extended to accommodate the determinants of transient and persistent inefficiency.

In recent years, a number of studies have analyzed technical efficiency in the dairy sector, but without its decomposition and including determinants of transient and persistent efficiency directly in the model (see, e.g., Zhu et al., 2012; Latruffe et al., 2011; Madau et al., 2017; Latruffe et al., 2016).

Hence, to our knowledge, this is the first study analyzing the determinants of transient and persistent efficiency of milk production in the EU taking into account all member states and a longer time period. The main objective of this paper is to:

1. measure and compare the technical efficiency of milk production in each EU member state;

2. decompose the overall efficiency into transient and persistent part for each EU member state and make a comparison;

3. determine factors affecting transient and persistent efficiency.

The rest of the paper is organized as follows. Firstly, we begin by a literature review in section 1 , after that we introduce the used data and the four-component SF model with determinants of transient and persistent efficiency in section 3 . In the next step, we present empirical results in section 4. Finally, we draw some conclusions.

\section{Theoretical Background}

The overall technical efficiency can be decomposed into persistent (long-run) inefficiency and transient (short-run) inefficiency. According to Njuki and Bravo-Ureta (2015), the long-run inefficiency may vary across firms for various reasons, which include prior institutional and statutory regimes. This type of inefficiency could arise due to the presence of rigidity within a firm's organization and production process. The short-run inefficiency may vary because of shocks associated with new production technologies, human capital, and learning-by-doing. Moreover, according to Filippini and Greene (2014), the transient part may be due to the presence of nonsystematic management problems that can be solved in the short term. This distinction has significant political implications because, according to Kumbhakar et al. (2014), the persistent part of technical inefficiency is unchangeable without a new policy or change in ownership and management of companies. Another look bring Agasisti and Gralka (2017), they mention that transient efficiency, reflecting annual influences, therefore presumable occurs at the institutional level and represents an institutional efficiency. In contrast, persistent efficiency, being a constant factor, reflects the influence of the higher level, representing a structural efficiency.

Kumbhakar et al. (2014), Colombi et al. (2014) and Tsionas and Kumbhakar (2014) at the same time introduce the four-component 
error-term SF model, which just allows the estimation of the persistent and transient parts of inefficiency from the same data. The four components are: firms' latent heterogeneity, persistent inefficiency, transient inefficiency, and random shocks. According to Alem (2018), the first component captures the random shocks that are out of the control of the farm manager (weather, disease, and pest infestation). The second component captures latent heterogeneity, which is distinguished from the inefficiency. The third component captures longrun inefficiency. The last component captures short-run inefficiency (Kumbhakar et al., 2014). Tsionas and Kumbhakar (2014) named the four components model the generalized true random-effects model (GTRE).

The above-mentioned model is applied to various economic sectors across various economies. For example, Filippini et al. (2016) use the four-component model for ananalysis of electricity distribution, Colombi et al. (2017) for ananalysis of hospital efficiency, Heshmati et al. (2018) for an analysis of international airlines, Agasisti and Gralka (2017) for an analysis of efficiency of Italian and German universities, Njuki et al. (2016) for an analysis of environmental efficiency in U.S. dairy farming, etc. However, it was only recently applied to the agricultural sector (Kumbhakar et al. (2014) and later Lien et al. (2018) using data on grain farmers in Norway, Pisulewski and Marzec (2019) using data of Polish crops farms, and Addo and Salhofer (2019) using data of Austrian crop farms).

However, Lien et al. (2018) emphasize the need to include determinants in the model, especially when the inefficiency components are assumed to independently and identically distributed random variables. But only very few authors deal with the analysis of determinants of transient and persistent technical efficiency, which are included in the above mentioned fourcomponent model, for example, Colombi et al. (2017), Badunenko and Kumbhakar (2016), Lai and Kumbhakar (2018), Heshmati et al. (2018) and for agriculture Lien et al. (2018) and Addo and Salhofer (2019).

Lien et al. (2018) also state three groups of variables which have generally been studied as inefficiency determinants: characteristics of farm and technology employed, location and environmental variables characterizing the conditions for farming, and human capital variables. Some determinants will have a longrun effect on efficiency (persistent) while others are more likely to be time-variant and short term (transient).

The understanding of the determinants of transient and persistent inefficiency components might be desirable for policy purposes, especially, according to Badunenko and Kumbhakar (2016), in regulated industries. For example, establishing determinants of persistent inefficiency could help decisionmakers to develop strategies to remove long-term impediments, such as too rigid regulations or other structural rigidities. On the other hand, transient inefficiency can be due to bad luck, management mistakes, etc, that can get corrected. Knowledge about these drivers of transient inefficiency may help in improving the efficiency of individual farms in the short run.

Lien et al. (2018) analyze determinants of inefficiency in Norwegian crop-producing farms using the four-component SF model that includes determinants of only transient inefficiency using an extension of multistep procedure used in Kumbhakar et al. (2014). One-step estimation approaches were presented in, e.g., Lai and Kumbhakar (2018) and Badunenko and Kumbhakar (2017). While only transient inefficiency in Lien et al. (2018) is explained (by off-farm activity and subsidies), the authors mention, that it is logical to use different $Z$ variables as determinants for transient and persistent inefficiency. The variables explaining persistent inefficiency should naturally be time-invariant (e.g. regional location, education, experience, a period with persistent policy regime, etc).

Addo and Salhofer (2019) apply a multistep four-error component model introduced by Kumbhakar et al. (2014) for analyzing the efficiency of Austrian crop farms and assess the impact of farm and farmer characteristics on both types of technical inefficiency. These determinants should explain the potential differences in transient and persistent technical inefficiencies. Farm characteristics include crop specialization, subsidy dependence, shares of own land and family labour and farm size. The characteristics of the farm manager include age and level of education. The results showed that persistent inefficiency is influenced by education, subsidy share, crop specialization, own land share and farm size. They observe 
that subsidy share, family labour share, crop specialization and time impacted transient inefficiency. As mentioned above, there are no empirical studies examining the determinants of transient and persistent efficiency in milk production.

\section{Data and Methods}

\subsection{Data Description}

The analysis uses unbalanced panel data set of TF14-45 specialist milk drawn from the FADN database via Dynamic reporting tool (Data Warehouse: Standard Output, Type of report: Year*Country*Region*TF14). The data covers the period 2004-2017 and 27 European Union member states. No data was available for specialized milk production in Cyprus and Greece. The data set consists of 1,449 observations of FADN regions. Although regional data represent the lowest level of aggregation freely available in the FADN database, it introduced several limitations to the analysis. These limitations are discussed by Madau et al. (2017).

The FADN database provides harmonised microeconomic data (physical as well as financial data). Our analysis uses the following variables: total labour input in annual work unit - AWU (FADN code: SE010); (SE020); total utilised agriculture area in hectares (SE025); rented utilised agriculture area in hectares (SE030); total livestock units (SE080); production of milk and milk products in kilos (SE125N); (SE131); total output of crops and crops products in EUR (SE135); total output of livestock and livestock products in EUR (SE206); cows' milk and milk products in EUR (SE216); forestry products, contracted work for others and other outputs in EUR (SE256); total costs link to agriculture activity in EUR (SE270); total specific costs and overheads arising from production in the accounting year in EUR (SE275); feed for grazing livestock in EUR (SE310); feed for grazing livestock homegrown in EUR (SE315); cost link to work carried out by contractors and hired machinery in EUR (SE350); depreciation in EUR (SE360); subsidies link to production (not investments) in EUR (SE605); all farm subsidies on livestock and livestock products in EUR (SE615); LFA subsidies in EUR (SE622).

Outputs, as well as inputs (except for the milk production, labour, and land), are deflated by price indices (individual output and input indices $(2010=100)$ - source the EUROSTAT database (apri_pi10_ina and apri_pi10_out)).

\subsection{Research Methodology}

The analysis is based on an assumption that the transformation process is well approximated by the input-distance function (IDF) with the following properties: symmetry, monotonicity, linear homogeneity and concavity in inputs and quasi-concavity in outputs (Greene, 2005). We prefer the input-orientation over the output one due to the prevailing existence of milk quotas in the analyzed period 2004-2017 that represent a strong restriction on the maximum quantity of milk production and caused that agricultural producers focus primarily on reducing inputs to produce almost fixed output (see Kumbhakar et al., 2008). In other words, the goal of profit maximization can be achieved by minimizing the cost of producing a fixed output. Under this optimization condition, the outputs can be assumed as exogenous, see Skevas et al. (2018).

The IDF is estimated in a translog functional form. This second-order local approximation of any twice-differentiable function satisfied Diewert's minimum flexibility requirement for flexible form (see Pisulewski \& Marzec, 2019). The translog input distance function for two outputs $(y)$, five inputs $(x)$ and time $(t)$ is defined as:

$$
\begin{aligned}
& \ln D_{i t}^{I}=\alpha_{0}+\sum_{m=1}^{2} \beta_{m} \ln y_{m, i t}+ \\
& +\frac{1}{2} \sum_{m=1}^{2} \sum_{n=1}^{2} \beta_{m n} \ln y_{m, i t} \ln y_{n i, t}+ \\
& +\sum_{m=1}^{2} \sum_{j=1}^{5} \delta_{m j} \ln y_{m, i t} \ln x_{j, i t}+ \\
& +\sum_{j=1}^{5} \beta_{j} \ln x_{j, i t}+\frac{1}{2} \sum_{j=1}^{5} \sum_{k=1}^{5} \beta_{j k} \ln x_{j, i t} \ln x_{k, i t}+ \\
& +\alpha_{t} t+\frac{1}{2} \alpha_{t t} t^{2}+\sum_{m=1}^{2} \alpha_{m t} \ln x_{m, i t} t+ \\
& +\sum_{j=1}^{5} \alpha_{j t} \ln x_{j, i t} t
\end{aligned}
$$

where subscripts $i$, with $i=1,2, \ldots, N$, and $t$, with $t=1, \ldots, T$, refer to a certain FADN region and time (year), respectively. $\boldsymbol{\alpha}, \boldsymbol{\beta}$ and $\boldsymbol{\delta}$ are vectors of the parameters to be estimated. The symmetry restrictions imply that $\beta_{j k}=\beta_{k j}$ and $\beta_{m n}=\beta_{n m}$. The time trend included in IDF allows for capturing the joint effects of embedded knowledge, technology improvements and learning-by-doing in input quality improvements (see Čechura et al., 2017).

Implying the homogeneity property of IDF, the following generalized true random effect stochastic translog IDF can be estimated: 


$$
-\ln x_{1 i t}=A+w_{i}-u_{i 0}+v_{i t}-u_{i t},
$$

where $A=\alpha_{0}+\sum_{m=1}^{2} \beta_{m} \ln y_{m, i t}+$ $+\frac{1}{2} \sum_{m=1}^{2} \sum_{n=1}^{2} \beta_{m n} \ln y_{m, i t} \ln y_{n i, t}+$

$+\sum_{m=1}^{2} \sum_{j=2}^{5} \delta_{m j} \ln y_{m, i t} \ln \tilde{x}_{j, i t}+$

$+\sum_{j=2}^{5} \beta_{j} \ln \tilde{x}_{j, i t}+\frac{1}{2} \sum_{j=2}^{5} \sum_{k=2}^{5} \beta_{j k} \ln \tilde{x}_{j, i t} \ln \tilde{x}_{k, i t}+$

$+\alpha_{t} t+\frac{1}{2} \alpha_{t t} t^{2}+\sum_{m=1}^{2} \alpha_{m t} \ln y_{m, i t} t+$

$+\sum_{j=2}^{5} \alpha_{j t} \ln \tilde{x}_{j, i t} t$,

$v_{i t} \sim N\left(0, \sigma_{v}^{2}\right), u_{i t}=\left|U_{i t}\right|, U_{i t} \sim N\left(0, \sigma_{u, t}^{2}\right)$,

$w_{i}=\sigma_{w} W_{i}, W_{i} \sim N\left(0, \sigma_{w}^{2}\right), u_{i}=\left|U_{i}\right|, U_{i} \sim N\left(0, \sigma_{u 0}^{2}\right)$,

$\ln \tilde{X}_{j, i t}=\ln X_{j, i t}-\ln X_{1, i t}, j=2, \ldots, 5$.

Moreover, following Kumbhakar et al. (2014) the model can be rewritten as:

$$
\begin{aligned}
& -\ln x_{1 i t}=\alpha_{0}^{*}+\sum_{m=1}^{2} \beta_{m} \ln y_{m, i t}+ \\
& +\frac{1}{2} \sum_{m=1}^{2} \sum_{n=1}^{2} \beta_{m n} \ln y_{m, i t} \ln y_{n i, t}+ \\
& +\sum_{m=1}^{2} \sum_{j=2}^{5} \delta_{m j} \ln y_{m, i t} \ln \tilde{x}_{j, i t}+ \\
& +\sum_{j=2}^{5} \beta_{j} \ln \tilde{x}_{j, i t}+\frac{1}{2} \sum_{j=2}^{5} \sum_{k=2}^{5} \beta_{j k} \ln \tilde{x}_{j, i t} \ln \tilde{x}_{k, i t}+ \\
& +\alpha_{t} t+\frac{1}{2} \alpha_{t t} t^{2}+\sum_{m=1}^{2} \alpha_{m t} \ln y_{m, i t} t+ \\
& +\sum_{j=2}^{5} \alpha_{j t} \ln \tilde{x}_{j, i t} t+\alpha_{i}+\varepsilon_{i t},
\end{aligned}
$$

where $\quad \alpha_{0}^{*}=\alpha_{0}-E\left(u_{i 0}\right)-E\left(u_{i t}\right), \alpha_{i}=w_{i}-$ $-\left(u_{i 0}-E\left(u_{i 0}\right)\right)$ and $\varepsilon_{i t}=v_{i t}-\left(u_{i t}-E\left(u_{i t}\right)\right)$.

According to Sipiläinen et al. (2014) and Kumbhakar (2011a), the normalization ensures the exogeneity of inputs and consistency of estimation. Furthermore, the normalization of all variables in logarithm by their sample means makes possible to interpret the estimated firstorder parameters as elasticities at the geometric mean of the sample.

According to Kumbhakar et al. (2014), the generalized true random effect model is estimated in three steps. In step 1, the standard random effect panel regression is used to estimate $\boldsymbol{\beta}, \boldsymbol{\delta}, \boldsymbol{\alpha}$ and theoretical values of $\alpha_{i}$ and $\varepsilon_{i t}$, denoted by $\hat{\alpha}_{i}$ and $\widehat{\varepsilon_{t t}}$. We use software $R$ 3.5.0, package PLM in this step. In step 2, the persistent technical inefficiency, $u_{i 0}$, is estimated using $\hat{\alpha}_{i}$ and the stochastic frontier model with the following assumptions based on Lien et al. (2018): $w_{i} \sim N\left(0, \sigma_{w}^{2}\right), u_{0 i}\left(z_{i}\right) \sim N^{+}\left(0, \sigma_{u 0}^{2}\left(z_{i}\right)\right)$, where $z_{i}$ are determinants of persistent technical efficiency. Finally, according to Lien et al. (2018) transient technical inefficiency, $u_{i t}$, is estimated using $\widehat{\varepsilon_{l t}}$ and the standard stochastic frontier technique with $v_{i t} \sim N\left(0, \sigma_{v}^{2}\right), u_{i t}\left(z_{i t}\right) \sim N^{+}\left(0, \sigma_{u, t}^{2}\left(z_{i t}\right)\right)$, where $Z_{i t}$ are determinants of transient technical inefficiency. According to Wang (2002), the derivation of the average marginal effects of the factors explaining the heteroscedasticity of the one-sided error components is used to analyze the effects of determinants on persistent and transient technical efficiency. These steps are done in the SW NLOGIT 5.0. Furthermore, the total technical efficiency (OTE) is quantified based on Kumbhakar et al. (2014):

$$
O T E_{i t}=\exp \left(-\hat{u}_{i 0}\right) * \exp \left(-\hat{u}_{i t}\right) .
$$

For the estimation of the IDF in this study, we use the following outputs and inputs: milk production $\left(y_{1}\right)(\mathrm{SE} 125 \mathrm{~N})$, other production $\left(y_{2}\right)$, which is determined as the sum of crop production (SE135), other animal production (SE206 minus the production of milk (SE216)) and other production (SE256), the cost of feed for grazing livestock $\left(x_{1}\right)$ (SE310), labour $\left(x_{2}\right)$ (SE010), the total utilized agriculture area $\left(x_{3}\right)$ (SE025), capital $\left(x_{4}\right)$ measured as the depreciation (SE360) plus contracted work (SE350) and the costs of other materials $\left(x_{5}\right)$ (total intermediate consumption (SE275) minus feed for grazing livestock (SE310)).

The transient inefficiency determinant variables in this study consist of the following: the share of paid labour $\left(z_{1}\right.$, SE020/SE010), the share of rented land $\left(z_{2}\right.$, SE030/SE025), the level of modernization $\left(z_{3}\right)$ measured as a ratio of depreciation and total cost (SE360/ SE270), the off-farm activity $\left(z_{4}\right)$ defined as a ratio of other output to total output (SE256/SE131), the level of total subsidies on livestock per livestock unit $\left(z_{5}, \quad\right.$ SE615/SE080). The persistent inefficiency determinant variables in this study consist of the following: the farm specialization $\left(z_{6}\right)$ defined as the share of milk output on the total output (SE216/SE131), the economic size in $\operatorname{ESU}\left(z_{7}\right)$, and the share of Less Favoured Areas (LFA) subsidies on the total subsidies excluding on investment $\left(z_{8}\right.$, SE622/SE605). These determinants were selected based on previous research and statistical properties of estimates. Descriptive statistics of the variables used in the study are presented in Tab. 1.

According to Lien et al. (2018), the determinants of persistent technical inefficiency should be time-invariant. Therefore, the 
Tab. 1: Descriptive statistics ( $N=1,449)$

\begin{tabular}{c|l|r|r|r|r} 
Variable & \multicolumn{1}{c|}{ Label } & \multicolumn{1}{c|}{ Mean } & \multicolumn{1}{c|}{ Std. Dev. } & \multicolumn{1}{c}{ Min. } & Max. \\
\hline \multicolumn{4}{c|}{ Input distance function variables } \\
\hline y1 & Milk production [kilos] & $433,072.9$ & $454,357.4$ & $7,526.2$ & $3,009,667.9$ \\
\hline y2 & Other production [ths. EUR 2010] & $68,481.9$ & $100,724.9$ & $1,153.0$ & $804,500.5$ \\
\hline x1 & Feed [ths. EUR 2010] & $60,823.8$ & $62,202.7$ & 762.5 & $352,099.8$ \\
\hline x2 & Labour [AWU] & 2.8 & 3.4 & 0.8 & 37.5 \\
\hline x3 & $\begin{array}{l}\text { Utilized Agricultural Area } \\
\text { [hectares] }\end{array}$ & 89.6 & 134.0 & 1.7 & 1041.9 \\
\hline x4 & Capital [ths. EUR 2010] & $38,598.4$ & $44,490.4$ & 456.9 & $352,911.8$ \\
\hline x5 & $\begin{array}{l}\text { Cost of other material [ths. EUR } \\
\text { 2010] }\end{array}$ & $82,732.8$ & $112,848.8$ & 938.5 & $734,496.0$ \\
\hline
\end{tabular}

Inefficiency determinant variables and heteroskedasticity variables in the inefficiency and error component function

\begin{tabular}{r|l|r|r|r|r}
\hline z1 & Share of paid labour & 0.229 & 0.238 & 0.000 & 0.986 \\
\hline z2 & Share of rented land & 0.606 & 0.244 & 0.000 & 0.995 \\
\hline z3 & Level of modernization & 0.150 & 0.063 & 0.013 & 0.360 \\
\hline z4 & Off-farm activity & 0.035 & 0.046 & 0.000 & 0.437 \\
\hline z5 & $\begin{array}{l}\text { Total subsidies on livestock [ths. } \\
\text { EUR/LU] }\end{array}$ & 58.094 & 117.765 & -110.750 & 1011.647 \\
\hline z7 & Specialization & 0.684 & 0.102 & 0.242 & 0.960 \\
\hline z8 & Economic size [ESU] & 191.844 & 223.720 & 4.200 & 1564.300 \\
\hline
\end{tabular}

Source: own

means of variables in $i^{\text {th }}$ region over the period 2004-2017 are used.

\section{Research Results}

The estimated parameters of the input distance function in translog specification are presented in Tab. 2 with the label of connected variables according to Chapter 2.2. Most of the estimated parameters are highly statistically significant, even at the $1 \%$ significance level. According to Färe and Primont (1995), an input distance function should be non-increasing in outputs, as well as non-decreasing in inputs. Tab. 2 shows that these conditions are met. Moreover, the estimated parameters satisfied the requirements of monotonicity resulted in $\beta_{j}>0$ for $j=2, . ., 5$ and $\sum_{j=2}^{5} \beta_{j}<1$ (see Čechura \& Hockmann, 2017). Since these theoretical assumptions hold, we can suppose that the model approximates well the real transformation process.
According to Irz and Thirtle (2004), the elasticities of the distance function with respect to input quantities equal to the cost-share and reflect the relative importance of the inputs in the production process. In line with this definition, we can conclude that the European milk production can be characterized by high labour intensity - the share of labour $\left(\beta_{x 2}\right)$ is $37 \%$. On the other hand, the share of capital $\left(\beta_{x 4}\right)$ in the total input is only $9 \%$. It is the lowest value from analyzed inputs. We can add that the share of land is $13 \%$. As can be expected, material (including feeds) has the highest share of the total costs. The similar cost structure was estimated for milk production based on IDF by Sipiläinen et al. (2014). The elasticity of milk $\left(\beta_{y 1}\right)$ that corresponds to the negative of the cost elasticity of the particular output (see Irz \& Thirtle, 2004), is about (-0.55). In line with our expectation, this indicates that the cost elasticity of milk is much larger than the 


\begin{tabular}{|c|c|c|c|c|c|c|c|}
\hline P. label & Coeff. & SE & $P[>|t|]$ & P. label & Coeff. & SE & $P[>|t|]$ \\
\hline$\alpha_{t}$ & 0.0060 & 0.0007 & 0.0000 & $\alpha_{y 1 t}$ & -0.0011 & 0.0017 & 0.5025 \\
\hline$\alpha_{\mathrm{tt}}$ & -0.0002 & 0.0003 & 0.4041 & $\boldsymbol{\alpha}_{\mathrm{y} 2 \mathrm{t}}$ & 0.0079 & 0.0011 & 0.0000 \\
\hline $\boldsymbol{\beta}_{\mathrm{y} 1}$ & -0.5480 & 0.0156 & 0.0000 & $\boldsymbol{\alpha}_{\mathrm{x} 2 \mathrm{t}}$ & 0.0103 & 0.0016 & 0.0000 \\
\hline $\boldsymbol{\beta}_{\mathrm{y} 2}$ & -0.1814 & 0.0094 & 0.0000 & $\boldsymbol{\alpha}_{\mathrm{x} 3 \mathrm{t}}$ & -0.0066 & 0.0014 & 0.0000 \\
\hline $\boldsymbol{\beta}_{\mathrm{x} 2}$ & 0.3743 & 0.0192 & 0.0000 & $\boldsymbol{\alpha}_{\mathrm{x} 4 \mathrm{t}}$ & 0.0087 & 0.0016 & 0.0000 \\
\hline $\boldsymbol{\beta}_{\mathrm{x} 3}$ & 0.1256 & 0.0199 & 0.0000 & $\boldsymbol{\alpha}_{x 5 t}$ & -0.0068 & 0.0024 & 0.0047 \\
\hline $\boldsymbol{\beta}_{\mathrm{x} 4}$ & 0.0899 & 0.0137 & 0.0000 & $\boldsymbol{\beta}_{\mathrm{x} 2 \times 2}$ & -0.0275 & 0.0418 & 0.5113 \\
\hline $\boldsymbol{\beta}_{\times 5}$ & 0.1685 & 0.0169 & 0.0000 & $\boldsymbol{\beta}_{\mathrm{x} 3 \times 3}$ & 0.0236 & 0.0316 & 0.4553 \\
\hline $\boldsymbol{\beta}_{\mathrm{y} 1 \mathrm{y} 1}$ & -0.1900 & 0.0323 & 0.0000 & $\boldsymbol{\beta}_{\mathrm{x} 4 \times 4}$ & 0.1544 & 0.0173 & 0.0000 \\
\hline $\boldsymbol{\beta}_{\mathrm{y} 2 \mathrm{y} 2}$ & -0.0974 & 0.0189 & 0.0000 & $\boldsymbol{\beta}_{\mathrm{x} 5 \times 5}$ & 0.3380 & 0.0250 & 0.0000 \\
\hline $\boldsymbol{\beta}_{\mathrm{y} 1 \mathrm{y} 2}$ & 0.0619 & 0.0198 & 0.0017 & $\boldsymbol{\beta}_{\mathrm{x} 2 \times 3}$ & -0.0330 & 0.0329 & 0.3161 \\
\hline$\delta_{\mathrm{y} 1 \times 2}$ & -0.0578 & 0.0289 & 0.0455 & $\boldsymbol{\beta}_{\mathrm{x} 2 \times 4}$ & 0.1346 & 0.0234 & 0.0000 \\
\hline$\delta_{y 1 \times 3}$ & 0.0016 & 0.0269 & 0.9537 & $\boldsymbol{\beta}_{\mathrm{x} 2 \times 5}$ & -0.1118 & 0.0354 & 0.0016 \\
\hline$\delta_{\mathrm{y} 1 \times 4}$ & 0.0511 & 0.0227 & 0.0241 & $\boldsymbol{\beta}_{\times 3 \times 4}$ & -0.0250 & 0.0178 & 0.1588 \\
\hline$\delta_{\mathrm{y} 1 \times 5}$ & -0.0942 & 0.0337 & 0.0052 & $\boldsymbol{\beta}_{\times 3 \times 5}$ & -0.0049 & 0.0286 & 0.8639 \\
\hline$\delta_{y 2 \times 2}$ & -0.0395 & 0.0225 & 0.0786 & $\boldsymbol{\beta}_{\times 4 \times 5}$ & -0.1388 & 0.0222 & 0.0000 \\
\hline$\delta_{y 2 \times 3}$ & -0.0196 & 0.0217 & 0.3659 & $\sigma_{v}$ & 0.0041 & & \\
\hline $\boldsymbol{\delta}_{\mathrm{y} 2 \times 5}$ & 0.0484 & 0.0173 & 0.0051 & $\sigma_{\alpha}$ & 0.0116 & & \\
\hline $\boldsymbol{\alpha}_{0}$ & -0.0087 & 0.0143 & 0.5447 & $\mathrm{R}^{2}$ & 0.9582 & & \\
\hline $\boldsymbol{\sigma}_{\mathrm{u} 0}$ & 0.1685 & $\sigma_{\mathrm{v} 0}$ & 0.0912 & $X^{2}[35]$ & $32,386.6$ & & 0.0000 \\
\hline $\boldsymbol{\sigma}_{\mathrm{ut}}$ & 0.0778 & $\boldsymbol{\sigma}_{\mathrm{vt}}$ & 0.0576 & & & & \\
\hline
\end{tabular}

Source: own

Note: SE denotes a standard error.

elasticity of other output $\left(\beta_{y 2}\right)$. The parameter of time trend variable $\left(\alpha_{t}\right)$ that was introduced to capture technical change (see Kumbhakar, $2011 \mathrm{~b}$ ) points to slight cost enhancement in analyzed period (by $0.6 \%$ per annum).

Tab. 2 shows also the variance parameters in transient, persistent technical inefficiency and random effects. Their rations, i.e. $\lambda_{0}=\sigma_{u 0} / \sigma_{v 0}$ and $\lambda_{0}=\sigma_{u t} / \sigma_{v t}$, higher than one in both cases, indicate the significance of technical inefficiency in residual variation. The variation in both technical inefficiencies is more pronounced than the variation in random components that is important to the accuracy of the transient and persistent technical efficiency estimates. The statistical properties of both types of efficiency as well as of their product - overall technical efficiency are presented in Tab. 3.
Fig. 1 adds kernel density distributions of the overall technical efficiency scores. The overall technical efficiency is relatively dense around the mean in the level of $68 \%$. That is, the specialized milk producers can save $32 \%$ of inputs on the sample average to produce the same volume of outputs. Only $25 \%$ of observations have overall technical efficiency lower than $64 \%$. The minimum value is estimated at $33 \%$. On the other hand, $25 \%$ of observation can be characterized by overall technical efficiency higher than $73 \%$ with the highest value at $89 \%$.

With the average sample score of $89 \%$, the transient technical efficiency is higher than the persistent one, this holds for mean as well as median level, and exhibits slightly greater variability, see also Fig. 2. According 
Tab. 3: Statistical description of overall, persistent and transient technical efficiency

\begin{tabular}{l|c|c|c|c|c|c|c} 
& Mean & Std. Dev. & Min. & Max. & Q25 & Q50 & Q75 \\
\hline Overall & 0.6842 & 0.0798 & 0.3256 & 0.8874 & 0.6360 & 0.6880 & 0.7299 \\
\hline Persistent & 0.7709 & 0.0692 & 0.4131 & 0.8949 & 0.7332 & 0.7822 & 0.8103 \\
\hline Transient & 0.8863 & 0.0488 & 0.7472 & 0.9919 & 0.8588 & 0.8720 & 0.8883 \\
\hline \multicolumn{4}{|c|}{ Source: own }
\end{tabular}

\section{Fig. 1: Distribution of overall technical efficiency}

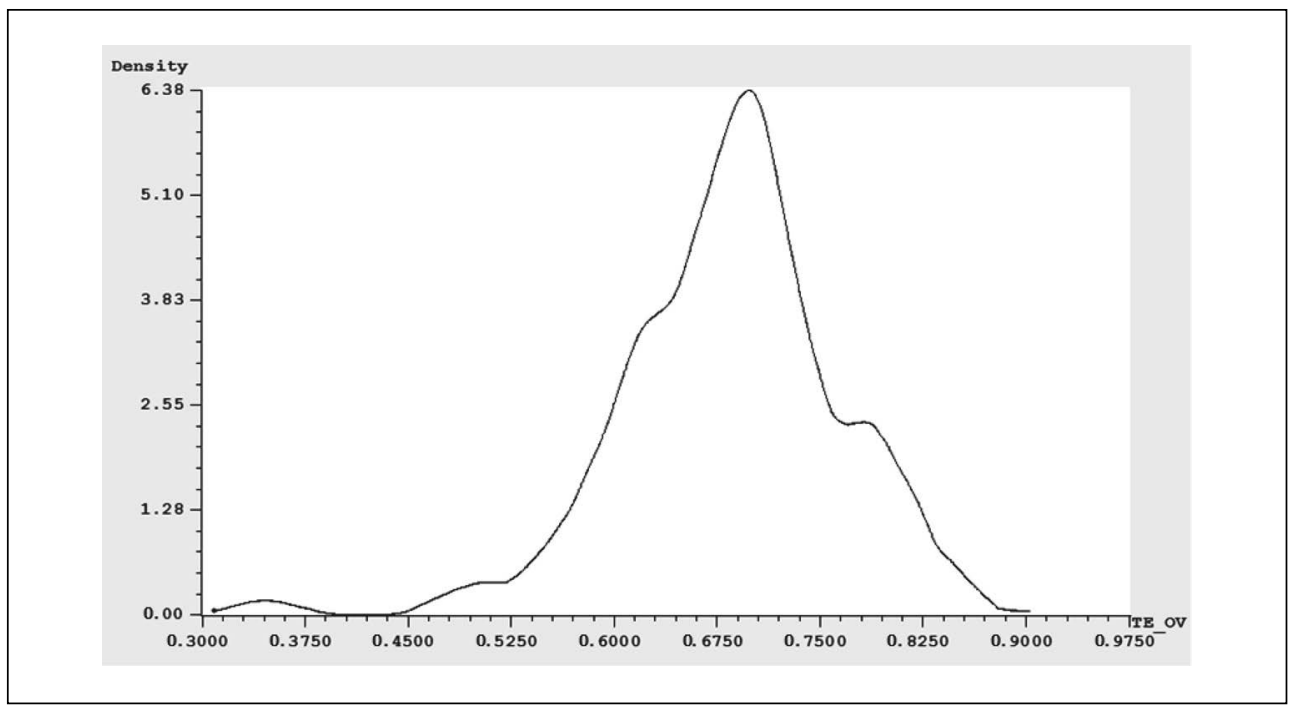

Source: own

to this result, we can conclude that the loss of resources is due to structural problems and permanent managerial failures in the production process. Therefore, to eliminate this loss of resources, agriculture policy should focus on factors affecting the persistent inefficiency. Moreover, we can conclude that in European milk production a high number of regions lag behind best practices in the short-term compared to the representation of the regions that are lagging behind in the long-time period.

According to Fig. 3, the transient efficiency fluctuates a lot over the observed period. Though transient technical efficiency of European milk production is generally slightly increasing over time, it decreased in the last years. We can suppose that the first significant decline - in the year 2010 - was a result of the economic crisis. Significant drops in the following period can be associated with milk crises caused by a surplus of milk on world markets on one side and by drought on the other side. In 2009, milk prices fell significantly and since then price volatility has become a more serious problem. The second milk crisis came in 2012 due to price decrease and costs increase. The third crisis started in 2015 and lasted until the third quarter of 2016. Raw milk prices went down and, as a result, margins too. The development of transient technical efficiency indicates the high sensitivity to the market situation (output, input price fluctuations) and the limited ability of dairy farms to manage shocks affecting shortterm production. 


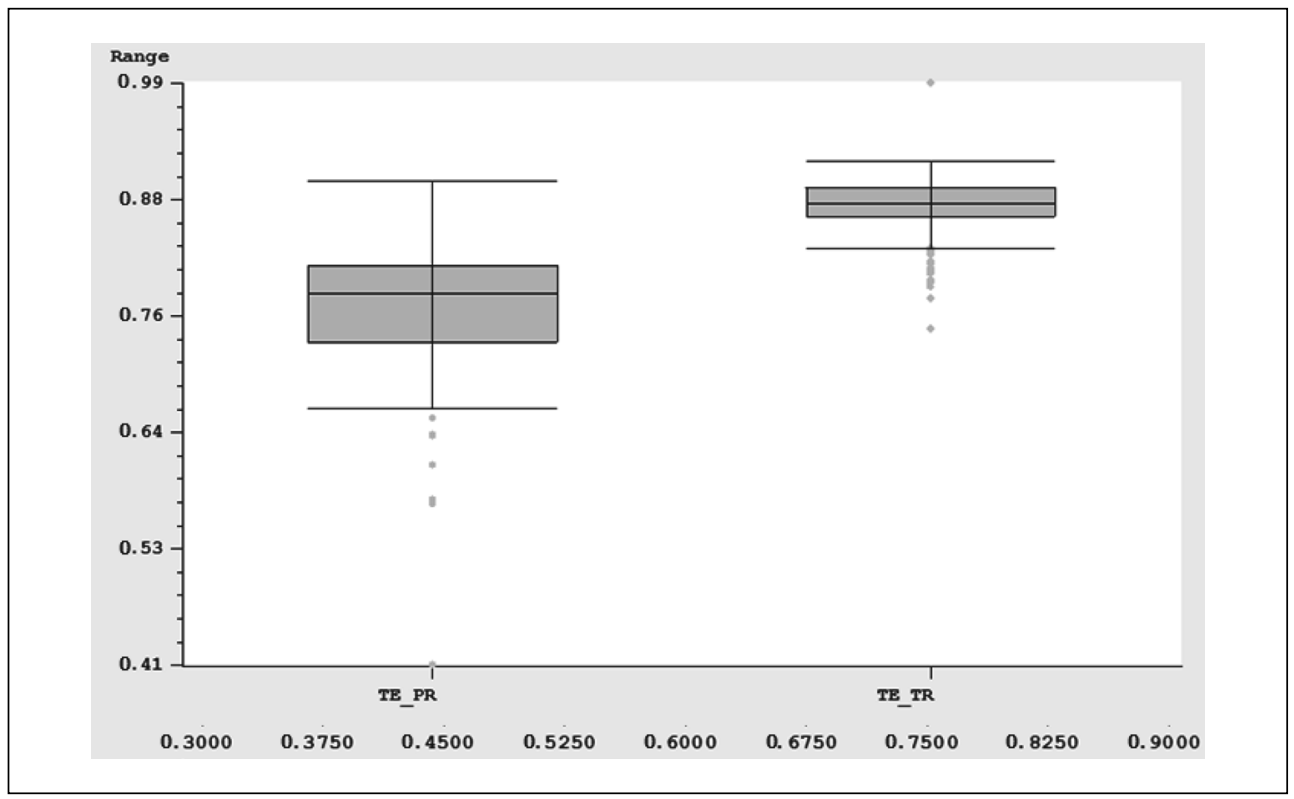

Source: own

The situation in European countries is presented in Fig. 4. The highest average value of overall technical efficiency at $81 \%$ was reached in the Netherlands. This finding is consistent with the research of Čechura et al. (2017). They analyzed time-variant technical efficiency of European dairy production based on the Fixed Management Model and farm- level panel data in 2004-2011. In the second and third positions are another two countries from so-called Milk Belt of EU - the United Kingdom and Belgium.

The Netherlands, Belgium and the United Kingdom hold also primacy in the efficiency of the transformation process in the long-term with the highest average value of persistent

\section{Fig. 3: Development of transient technical efficiency}

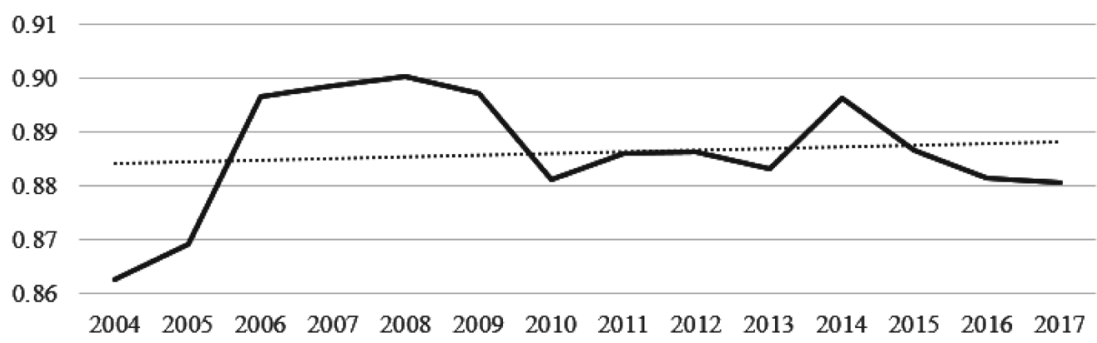




\section{Fig. 4: Overall, transient and persistent technical efficiency in European countries}

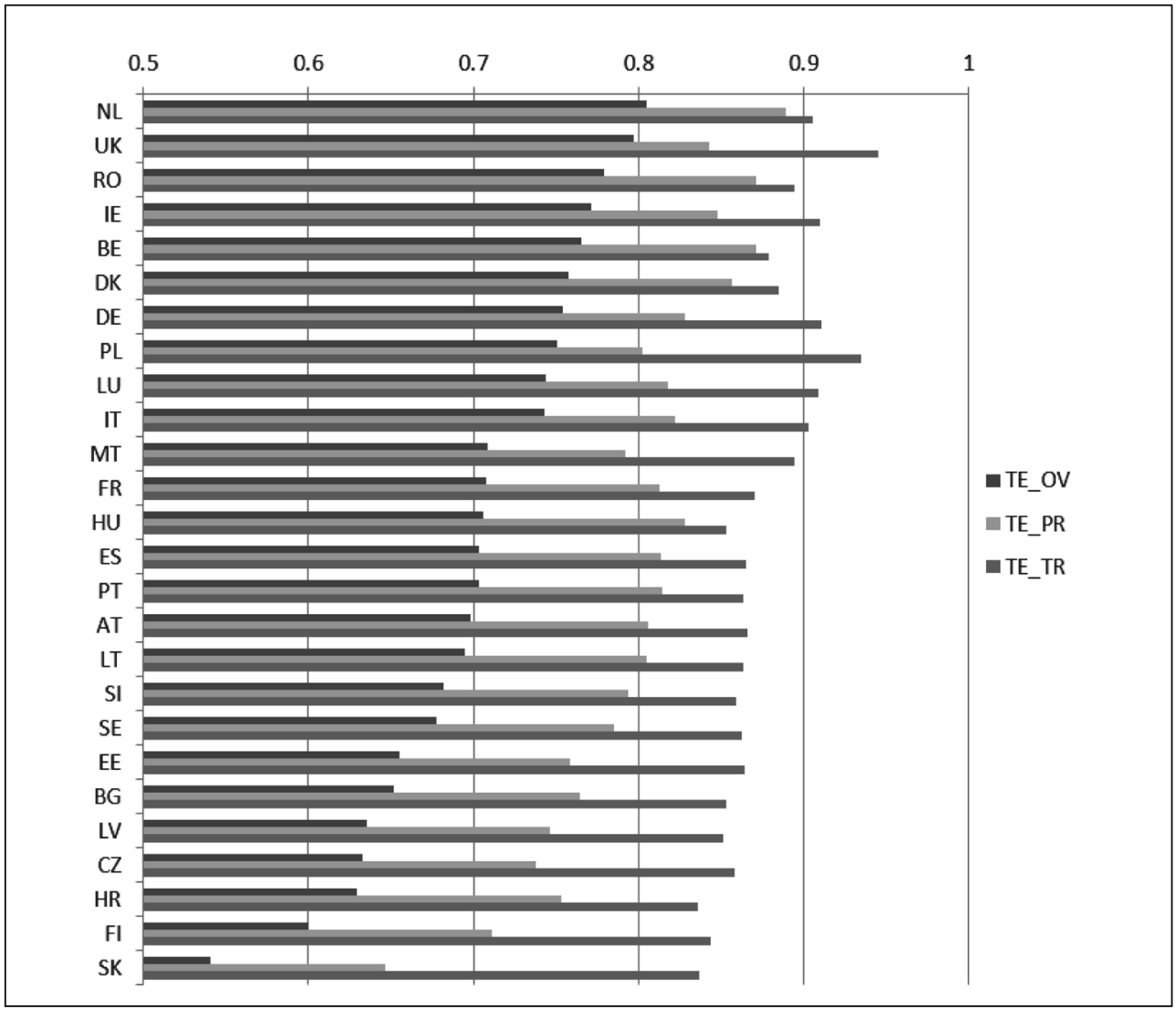

Source: own

efficiency. The dairy sector in these three countries is least burdened with long-term impediments, such as too rigid regulations or other institutional and structural rigidities. Moreover, the most effective conversion of inputs into outputs is a prerequisite for the high competitiveness of milk production in these countries.

In terms of short-run efficiency in the first position is the United Kingdom with $94.5 \%$, which is one of the top three countries with the highest overall efficiency. The UK is catching up with big EU milk producers - Germany and Poland. It can be said, milk production in these countries responds well to shocks, e.g. caused due to new technologies, and management mistakes are in general minimal.
The lowest mean value of the overall technical efficiency is found in Slovakia (35\%), further in the Czech Republic and Croatia. These countries are not a major player in dairy production in the European Union. Slovak and Czech agricultural, in general, are dominated by few large-scale and diversified farms with various alternative business activities. This fact results in very few farms being included in the FADN survey in a given specialization (TF14-45). It should be noted that more than $2 / 3$ of the Czech and Slovak milk production is produced by farms with mixed production (crops and livestock).

Due to diversified farms (whose crop production requires appropriate agricultural conditions), high-efficiency milk production takes place in other FADN specializations, 
and in the TF14-45 in both countries remain predominantly farms operating in less-favoured areas. The Czech and Slovak agriculture production can be characterized also by lower prices for land and labour, compared to other European regions, however, due to lower productivity of these factors (in particular with regard to labour) the positive effect on efficiency and performance in case TF14-45 in both countries is limited.

The persistent efficiency is also lowest in these three countries. Berisso (2019) states, that estimates of persistent inefficiencies provide useful information about farms because high persistent inefficiency scores are indicators of non-competitiveness. Therefore, in order to eliminate the long-term inefficiency, agricultural policy should focus on structural problems in the organization of the production process.

In terms of transient efficiency, Croatia is in the last position following by dairy farms in Slovakia. Following Njuki and Bravo-Ureta (2015), these inefficiencies may be the result of shocks associated with the introduction of new technologies or changes in human capital. To minimize them, it is recommended to support education and consulting services in these countries.

The distribution of transient and persistent technical efficiency can be explained by determinants that were included in the second and third steps of the four-component model estimation. According to Wang (2002), the coefficients of the determinants of inefficiency cannot be interpreted directly due to nonlinearity. Therefore, Tab. 4 presents the estimates of the marginal effects of determinants of persistent $\left(\left(u_{i 0}\right) / \partial z_{i}\right)$ and transient inefficiency $\left(\left(u_{i t}\right) / \partial z_{i t}\right)$. All marginal effects are statistically significant at the $1 \%$ significance level. Our results confirm that the transient inefficiency is influenced by paid labour share, rented land share, level of modernization, level of off-farm activity and level of subsidies on livestock. The persistent inefficiency is influenced by specialization, farm size, and localization of farms in LFA. However, it should be noted that the possibility of comparing the results with other authors dealing with determinants of transient and persistent efficiency of milk production is due to the novelty of the technical efficiency decomposition very limited.

The transient technical efficiency is significantly higher in regions where the milk producers employ more non-family employees $\left(z_{1}\right)$. This result is in line with Zhu and Lansink (2012) and Latruffe et al. (2016). The results of the analysis of dairy farms in Latruffe et al. (2016) indicate that a higher reliance on hired labour is positively associated with overall technical efficiency. Non-family employees may bring additional qualifications into the farm and may imply gains from task specialization. Also Kostov et al. (2018) according to Pollak (1985) mention some disadvantages of a family business. These include the possible toleration of inefficiency and slack performance, and the possible lack of talent and skills required for successful business performance. To these could be added the presence of non-economic objectives in family farming, such as to produce food for the household, provide employment to family members and preserve the farm for the next generation.

\section{Tab. 4: Average marginal effects of selected factors on the unconditional expected value of persistent and transient technical efficiency}

\begin{tabular}{|c|c|c|c|c|c|c|c|}
\hline \multicolumn{4}{|c|}{ Transient TE } & \multicolumn{4}{|c|}{ Persistent TE } \\
\hline Variab. & Partial effect & SE & $|t|$ & Variab. & Partial effect & SE & $|t|$ \\
\hline $\mathrm{z1}$ & 0.0011 & 0.0002 & 5.8800 & $z 6$ & 0.3153 & 0.0795 & 3.9700 \\
\hline $\mathrm{z2}$ & 0.0007 & 0.0003 & 2.0800 & $\mathrm{z} 7$ & -0.0026 & 0.0011 & 2.2600 \\
\hline z3 & 0.0015 & 0.0006 & 2.4800 & z8 & -0.0056 & 0.0014 & 4.1300 \\
\hline $\mathrm{z} 4$ & 0.0004 & 0.0001 & 5.6000 & & & & \\
\hline$z 5$ & -0.0071 & 0.0027 & 2.6800 & & & & \\
\hline \multicolumn{2}{|c|}{ LR-test, $\mathrm{HO}: \sigma \mathrm{u}=0$} & \multicolumn{2}{|c|}{$105.0^{* * *}$} & \multicolumn{2}{|c|}{ LR-test, $\mathrm{HO}: \sigma \mathrm{u}=0$} & \multicolumn{2}{|c|}{$642.1^{* * *}$} \\
\hline
\end{tabular}


The positive contribution of external factors is proved also based on the rented land $\left(z_{2}\right)$. We can conclude on the $5 \%$ level of significance that the share of rented land contributed to the transient technical efficiency increase. The higher share of rented land can improve performance due to the increased financial pressure because the obligation to pay rent appears to be a motivating factor for increasing efficiency of the transformation process and to a cost diminution. This result is consistent with Zhu and Lansink (2012) for dairy farms in Germany and Sweden and with Latruffe et al. (2016) for dairy farms in Spain, Italy, and the United Kingdom. Both papers have analyzed the technical efficiency of dairy farms in chosen European countries but without its decomposition into transient and persistent parts. However, authors do not reach a clear conclusion, because in some countries they found a positive relationship and in some countries a negative relationship. The same is true for the research of Bokusheva and Čechura (2017).

Milk production with a higher level of modernization is found to be more technically efficient (see $z_{3}$ ). The efficiency and hence the competitiveness of farms is inseparably linked to their investment activity, which is reflected in a higher share of depreciation in total costs. Our result is consistent with the paper of Nowak et al. (2016).

Diversification of production in terms of off-farm activities $\left(z_{4}\right)$ is estimated to improve transient technical efficiency. It is therefore not an extension of the portfolio to other agricultural activity. Off-farm activities (as, e.g., agri-tourism, processing of farm products or renewable energy production) provide a risk management tool to reduce the income variability, especially in short term. By engaging in off-farm activities, farms also become self-insured and they may invest in more advanced technology and modernization, which in turn provides higher technical efficiency. The analysis of Bojnec and Fertő (2013) on Slovenian farms confirms our finding that technical efficiency is slightly higher for farms with off-farm activities. They also explain the positive effect on technical efficiency due to the deployment of family farm households' surplus labour in off-farm employment and more efficient use of the remaining labour on the farm.
Finally, the support provided to farms in the form of livestock subsidies $\left(z_{5}\right)$ was found to decrease transient technical efficiency. The motivation of milk producers to work efficiently is lower when they depend on a higher degree on subsidies as a source of income. The higher subsidy dependence is found to be significantly associated with higher technical inefficiency, see for example Addo and Salhofer (2019), who analyzed the effect of subsidy share on persistent inefficiency in Austria, or Latruffe et al. (2011) in case of dairy farms in eleven EUcountries.

As expected, the specialization of production $\left(z_{6}\right)$ was estimated to improve persistent efficiency. Of all monitored determinants, specialization has the most significant impact on technical efficiency. The more specialized production can take advantage of more knowledge and a higher level of skills. This is similar to results reported by Addo and Salhofer (2019) concerning the effect of crop specialization on persistent efficiency in Austria, or Zhu and Lansink (2012) concerning the effect of milk specialization degree on technical efficiency. On the other hand, the estimates indicate that regions with larger producers tend to show lower persistent technical efficiency (see $z_{7}$ ). The positive effect of economies of scale was not proved. It should be noted that most authors dealing with the relationship of technical efficiency and farm size (measured by various indicators as ESU, agriculture area, and others), find a positive relationship. However, in this research, the relationship between size and long-term efficiency is analyzed, so it can be concluded, that the regions with larger producers are less flexible to changing market conditions and institutional framework and more burned with structural problems in the production process.

Milk production situated in Less Favoured Areas also tends to overuse persistently resources compared to best practice farms (see $z_{8}$ ). Regions outside the LFAs have better farming conditions for the production of feed (especially concentrated feed), resulting in achieving better results. Also, the paper of Latruffe et al. (2016) confirms for seven European countries a negative effect on efficiency. The effect of farm location and the degree of disadvantage on technical efficiency is also in the case of Czech farms confirmed by Rudinskaya et al. (2019). 


\section{Conclusions}

The goal of this paper was to estimate the technical efficiency and its persistent and transient part for dairy production in the European Union using an extension of the Kumbhakar et al. (2014) four random component SF model which allows observation of the determinants of transient and persistent efficiency. Attention was focused on specialized milk production using FADN data in the period from 2004 to 2017.

From a methodological point of view, the analysis was based on the currently most advanced approach to technical efficiency analysis and the multi-step estimation procedure extended by technical efficiency determinants. The main contribution of this paper is the practical application of the recently developed four-component model in the analysis of the efficiency of European dairy production, comparison of both types of technical efficiency on the country level and evaluation of the technical efficiency determinants. To the best of our knowledge, this is the first application of the four-component model based on the multi-step estimation with the inclusion of technical efficiency determinant on this type of specialization in the EU.

The overall technical efficiency achieves the mean value of $68 \%$ and is relatively dense around the mean. The transient technical efficiency with $89 \%$ is higher than the persistent efficiency with $77 \%$ and the scores of persistent efficiency are considerably more dispersed than the transient efficiency. It can be concluded, that persistent technical inefficiency poses a greater problem for dairy production in the EU. Based on the assessment of the development of transient efficiency, it is evident that it is influenced by the situation on the dairy market, in particular by the milk crises. However, it can be stated that price fluctuations have a similar impact on milk producers in all EU countries because the transient efficiency across the EU regions exhibits only low variability.

In terms of comparing technical efficiency in individual countries, the highest values of overall and persistent efficiency are achieved in the Netherlands, the United Kingdom, and Belgium. In these countries the conversion of inputs to outputs is most effective and is least burdened with institutional and structural rigidities. On the other hand, the big potential for improvement was found in Slovakia, the Czech Republic and
Croatia, where the average values of overall, persistent and also partially transient efficiency are the lowest.

Furthermore, we analyze factors that can explain both persistent and transient technical efficiency. The results showed that transient efficiency is positively influenced by paid labour share, rented land share, level of modernization and level of off-farm activities and negatively by the level of subsidies on livestock. According to our results, it cannot be stated, that the economies of size positively influence persistent efficiency, because the estimates indicate that regions with larger producers tend to show lower persistent technical efficiency. However, the positive effect on persistent efficiency has a specialization in milk production. It can be concluded that specialization is more important than size in order to increase technical efficiency. Localization of farms in LFAs, as expected, has a negative impact on persistent technical efficiency.

We can draw some policy implications from these insights because the improvement of the technical efficiency allows to more sustainable agriculture and brings competitive advantages. As was mentioned above, milk production in the EU is, in general, more persistent inefficient than transient and this inefficiency varies considerably across European regions. In order to improve the persistent efficiency agricultural policy should take into account the specifics of milk producers and production regions and support structural changes in low-efficient member states.

The persistent efficiency is positively affected by specialization. Despite the vulnerability of specialized farms to price shocks, it can still be said that specialization brings greater benefits. With this in mind, it can be stated, that possible tools for improving persistent inefficiency should involve knowledge transfer, support of agricultural education or new technologies thus everything that leads to be a "leader in its field". Transient efficiency should be supported by the implementation of such CAP subsidies, which provides incentives to improve efficiency and they are not just a source of income. The transient efficiency is positively affected by a higher level of modernization. With a view to increasing the efficiency of dairy production, we can recommend greater support for investment subsidies. 
Acknowledgement: The results are the part of the solution of project No. QK1920398 "Duality in Czech Agriculture: Advantage or Disadvantage for New Generation Agriculture?", supported by the Ministry of Agriculture of the Czech Republic, program "ZEMË" (EARTH).

\section{References}

Addo, F., \& Salhofer, K. (2019). Determinants of Persistent and Transient Technical Efficiency of Austrian Crop Farms. Paper presented at the 59th Annual Conference, Braunschweig, Germany, September 25-27, 2019, German Association of Agricultural Economists (GEWISOLA). https://doi.org/10.22004/ ag.econ.292287

Agasisti, T., \& Gralka, S. (2017). The transient and persistent efficiency of Italian and German universities: A stochastic frontier analysis (Working Paper No 14/17). Dresden: Technische Universität Dresden, Center of Public and International Economics (CEPIE).

Alem, H. (2018). Effects of model specification, short-run, and long-run inefficiency: an empirical analysis of stochastic frontier models. Agricultural Economics (Czech Republic), 64, 508-516. https://doi. org/10.17221/341/2017-AGRICECON

Badunenko, O., \& Kumbhakar, S. C. (2016). When, where and how to estimate persistent and transient efficiency in stochastic frontier panel data models. European Journal of Operational Research, 255(1), 272-287. https://doi.org/10.1016/j.ejor.2016.04.049

Badunenko, O., \& Kumbhakar, S. C. (2017). Economies of scale, technical change and persistent and time-varying cost efficiency in Indian banking: Do ownership, regulation and heterogeneity matter? European Journal of Operational Research, 260(2), 789-803. https://doi.org/10.1016/j.ejor.2017.01.025

Berisso, O. (2019). Analysis of Factors Affecting Persistent and Transient Inefficiency of Ethiopia's Smallholder Cereal Farming. In P. Nilsson \& A. Heshmati (Eds.), Efficiency, Equity and Well-Being in Selected African Countries Economic Studies in Inequality, Social Exclusion and Well-Being (pp. 199-228). Cham: Springer. https://doi.org/10.1007/978-3030-11419-0_10

Bojnec, ড̌s., \& Fertő, I. (2013). Farm income sources, farm size and farm technical efficiency in Slovenia. Post-Communist Economies,
25(3), 343-356. https://doi.org/10.1080/14631 377.2013.813140

Bokusheva, B., \& Čechura, L. (2017). Evaluating dynamics, sources and drivers of productivity growth at the farm level (OECD Food, Agriculture and Fisheries Paper No. 106). Paris: OECD Publishing. https://doi. org/10.1787/5f2d0601-en

Colombi, R., Kumbhakar, S. C., Martini, G., \& Vittadini, G. (2014). Closed-skew normality in stochastic frontiers with individual effects and long/short-run efficiency. Journal of Productivity Analysis, 42(2), 123-136. https://doi.org/10.1007/s11123-014-0386-y

Colombi, R., Martini, G., \& Vittadini, G. (2017). Determinants of transient and persistent hospital efficiency: The case of Italy. Health Economics, 26(S2), 5-22. https://doi. org/10.1002/hec.3557

Čechura, L., Grau, A., Hockmann, H., Levkovych, I., \& Kroupová, Z. (2017). Catching Up or Falling Behind in European Agriculture: The Case of Milk Production. Journal of Agricultural Economics, 68(1), 206-227. https://doi.org/10.1111/1477-9552.12193

Čechura, L., \& Hockmann, H. (2017). Heterogeneity in Production Structures and Efficiency: An Analysis of the Czech Food Processing Industry. Pacific Economic Review, 22(4), 702-719. https://doi.org/10.1111/14680106.12217

European Parliament. (2018). The EU dairy sector - Main features, challenges and prospects. Retrieved December 10, 2018, from http://www.europarl.europa.eu/ RegData/etudes/BRIE/2018/630345/EPRS_ BRI(2018)630345_EN.pdf.

Irz, X., \& Thirtle, C. (2004). Dual Technological Development in Botswana Agriculture: A Stochastic Input Distance Function Approach. Journal of Agricultural Economics, 55(3), 455-478. https://doi. org/10.1111/j.1477-9552.2004.tb00110.x

Färe, R., \& Primont, D. (1995). Multi-output production and duality: Theory and application. Boston, MA: Kluwer Academic Publishers.

Filippini, M., \& Greene, W. H. (2014). Persistent and Transient Productive Inefficiency: A Maximum Simulated Likelihood Approach (Working Paper No. 14/197). Zurich: CER-ETH - Center of Economic Research. https://doi.org/10.2139/ssrn.2440704

Filippini, M., Greene, W., \& Masiero, G. (2016). Persistent and transient productive 
inefficiency in a regulated industry: electricity distribution in New Zealand (IdEP Economic Paper No. 1603). Lugano: USI Università della Svizzera italiana.

Greene, W. (2005). Reconsidering heterogeneity in panel data estimators of the stochastic frontier model. Journal of Econometrics, 126(2), 269-303. https://doi. org/10.1016/j.jeconom.2004.05.003

Heshmati, A., Kumbhakar, S. C., \& Kim, J. (2018). Persistent and Transient Efficiency of International Airlines. European Journal of Transport and Infrastructure Research, 18(2), 213-238. https://doi.org/10.18757/ ejtir.2018.18.2.3231

Kostov, P., Davidova, S., \& Bailey, A. (2018). Effect of family labour on output of farms in selected EU Member States: a non-parametric quantile regression approach. European Review of Agricultural Economics, 45(3), 367-395. https://doi.org/10.1093/erae/jbx036

Kumbhakar, S. C. (2011a). Estimation of production technology when the objective is to maximize return to the outlay. European Journal of Operational Research, 208(2), 170176. https://doi.org/10.1016/j.ejor.2010.09.015

Kumbhakar, S. C. (2011b). Estimation of Multiple Output Production Functions. Paper presented at the North American Productivity Workshop, June 2-5, 2010, Rice University, Houston, Texas; and Asia-Pacific Productivity Conference, July 21-23, 2010, Taipei, Taiwan.

Kumbhakar, S. C., Lien, G., Flaten, O., \& Tveterås, R. (2008). Impacts of Norwegian Milk Quotas on Output Growth: A Modified Distance Function Approach. Journal of Agricultural Economics, 59(2), 350-369. https://doi. org/10.1111/j.1477-9552.2008.00154.x

Kumbhakar, S. C., Lien, G., \& Hardaker, J. B. (2014). Technical efficiency in competing panel data models: a study of Norwegian grain farming. Journal of Productivity Analysis, 41(2), 321-337. https://doi.org/10.1007/s11123-0120303-1

Lai, H.-P., \& Kumbhakar, S. C. (2018). Panel data stochastic frontier model with determinants of persistent and transient inefficiency. European Journal of Operational Research, 271(2), 746-755. https://doi.org/10.1016/j. ejor.2018.04.043

Latruffe, L., Bravo-Ureta, B., Moreira, V., Desjeux, Y., \& Dupraz, P. (2011). Productivity and subsidies in European Union countries: An analysis for dairy farms using input distance frontiers. Paper presented at EAAE 2011 Congress Change and Uncertainty, August 30-September 2, 2011, Zürich, Switzerland. https://doi.org/10.22004/ag.econ.114396

Latruffe, L., Bravo-Ureta, B. E., Carpentier, A., Desjeux, Y., \& Moreira, V. H. (2016). Subsidies and Technical Efficiency in Agriculture: Evidence from European Dairy Farms. American Journal of Agricultural Economics, 99(3), 783-799. https://doi. org/10.1093/ajae/aaw077

Lien, G., Kumbhakar, S. C., \& Alem, H. (2018). Endogeneity, heterogeneity, and determinants of inefficiency in Norwegian crop-producing farms. International Journal of Production Economics, 201, 53-61. https://doi. org/10.1016/j.ijpe.2018.04.023

Madau, F. A., Furesi, R., \& Pulina, P. (2017). Technical efficiency and total factor productivity changes in European dairy farm sectors. Agricultural and Food Economics, 5(1), 17. https://doi.org/10.1186/s40100-017-0085-x

Nowak, A., Kijek, T., \& Domańska, K. (2016). Technical efficiency and its determinants in the European Union. Agricultural Economics (Czech Republic), 61(6), 275-283. https://doi. org/10.17221/200/2014-agricecon

Njuki, E., \& Bravo-Ureta, B. E. (2015). The Economic Costs of Environmental Regulation in U.S. Dairy Farming: A Directional Distance Function Approach. American Journal of Agricultural Economics, 97(4), 1087-1106. https://doi.org/10.1093/ajae/aav007

Njuki, E., Bravo-Ureta, B. E., \& Mukherjee, D. (2016). The good and the bad: Environmental efficiency in Norrheastern U.S. Dairy Farming. Agricultural and Resource Economics Review, 45(1), 22-43. https://doi.org/10.1017/ age.2016.1

Pisulewski, A., \& Marzec, J. (2019). Heterogeneity, transient and persistent technical efficiency of Polish crop farms. Spanish Journal of Agricultural Research, 17(1), e0106. https://doi.org/10.5424/sjar/2019171-13926

Pollak, R. (1985). A transaction cost approach to families and households. Journal of Economic Literature, 23(2), 581-608.

Rasmussen, S. (2010). Scale efficiency in Danish agriculture: an input distance-function approach. European Review of Agricultural Economics, 37(3), 335-367. https://doi. org/10.1093/erae/jbq023

Rudinskaya, T., Hlavsa, T., \& Hruska, M. (2019). Estimation of technical efficiency 


\section{Economics}

of Czech farms operating in less favoured area. Agricultural Economics (Czech Republic), 65(10), 445-453. https://doi. org/10.17221/52/2019-agricecon

Sipiläinen, T., Kumbhakar, S. C., \& Lien, G. (2014). Performance of dairy farms in Finland and Norway from 1991 to 2008. European Review of Agricultural Economics, 41(1), 63-86. https://doi.org/10.1093/erae/jbt012

Skevas, I., Emvalomatis, G., \& Brümmer, B. (2018). Heterogeneity of Long-run Technical Efficiency of German Dairy Farms: A Bayesian Approach. Journal of Agricultural Economics, 69(1), 58-75. https://doi.org/10.1111/14779552.12231
Tsionas, E. G., \& Kumbhakar, S. C. (2014). Firm heterogeneity, persistent and transient technical inefficiency: A generalized true random-effects model. Journal of Applied Econometrics, 29(1), 110-132. https://doi. org/10.1002/jae.2300

Wang, H.-J. (2002). Heteroskedasticity and non-monotonic efficiency effects of a stochastic frontier model. Journal of Productivity Analysis, 18(3), 241-253. https://doi.org/10.1023/A:1020638827640

Zhu, X., Demeter, R. M., \& Oude Lansink, A. G. J. M. (2012). Technical efficiency and productivity differentials of dairy farms in three EU countries: the role of CAP subsidies. Agricultural Economics Review, 13(1), 66-92. https://doi.org/10.22004/ag.econ.253496 